\title{
High-resolution remote sensing image-based extensive deformation-induced landslide displacement field monitoring method
}

\author{
Shanjun Liu' ${ }^{1} \cdot$ Han Wang ${ }^{1} \cdot$ Jianwei Huang ${ }^{1} \cdot \operatorname{Lixin} \mathrm{Wu}^{1,2}$
}

Received: 31 March 2015/Revised: 30 June 2015/ Accepted: 31 July 2015/Published online: 23 September 2015

(C) The Author(s) 2015. This article is published with open access at Springerlink.com

\begin{abstract}
Landslide is one of the multitudinous serious geological hazards. The key to its control and reduction lies on dynamic monitoring and early warning. The article points out the insufficiency of traditional measuring means applied for large-scale landslide monitoring and proposes the method for extensive landslide displacement field monitoring using highresolution remote images. Matching of cognominal points is realized by using the invariant features of SIFT algorithm in image translation, rotation, zooming, and affine transformation, and through recognition and comparison of characteristics of high-resolution images in different landsliding periods. Following that, landslide displacement vector field can be made known by measuring the distances and directions between cognominal points. As evidenced by field application of the method for landslide monitoring at West Open Mine in Fushun city of China, the method has the attraction of being able to make areal measurement through satellite observation and capable of obtaining at the same time the information of largearea intensive displacement field, for facilitating automatic delimitation of extent of landslide displacement vector field and sliding mass. This can serve as a basis for making analysis of laws governing occurrence of landslide and adoption of countermeasures.
\end{abstract}

Keywords Landslide monitoring · High-resolution remote sensing · SIFT algorithm · Deformation field

\section{Introduction}

Landslide is a phenomenon of flow of rock-earth mass on slope along the shear fracture plane and often poses threats to people's life and leads to destruction of property, environment and resources. As a severe geological hazard, the key to its control and reduction lies in its dynamic monitoring and early warning.

The traditional landslide monitoring methods include precise geodetic survey, GPS monitoring, etc. (Brunner et al. 2007). These methods belong to spot measuring

\section{Shanjun Liu}

liusjdr@126.com

1 College of Resources and Civil Engineering, Northeastern University, Shenyang 110819, China

2 IOT Perception Mine Research Center, China University of Mining and Technology, Xuzhou 220116, China means and it is difficult for them to obtain the information on spatial displacement field. In recent years, interferometry synthetic aperture radar (InSAR) is becoming an important satellite-based microwave remote sensing technique, possessing significant advantages in the precise analysis of landslides over large areas, and could provide valuable temporal and spatial evolution information of surface deformation with a centimeter to millimeter accuracy in all weather conditions for landslide monitoring, especially for detecting small and slow motions during landslide's incipient stage ( $\mathrm{Hu}$ and $\mathrm{Hu} 2007$; Prati et al. 2010; Sun et al. 2015). 3D laser scanning is capable of providing high resolution required for analyzing movements and deformations of a landslide. Liu et al. (2015) improved the Hausdorff distance algorithm,and presented direct precise comparison algorithm based on octree structure. Ghuffar et al. (2013) used the range flow algorithm to determine the 3D motion of an active landslide in Doren, Austria by multitemporal airborne and terrestrial 
laser scanning. But above methods have both specific advantages and certain shortcomings. As a high-accuracy technique for the monitoring of surface deformation field, InSAR is liable to disposing of loss of phase correlation and phase unwrapping when measurement is made at places where the surface is undulating and extensive slope deformation occurs. The terrestrial 3D laser scanning technique is subject to the restriction of measuring range, and the airborne 3D laser scanning equipment is high in cost and complicated in measuring process, making it hard to realize widespread application.

On the other hand, the high resolution images are applied to monitor landslide hazards, mainly focus on the identification of landslide existence, dangerous evaluation and change detection. Nichol et al. applied the IKONOS stereo images to investigation and demonstration in remote sensing techniques for detailed landslide hazard assessment of large areas (Nichol et al. 2006). Gomeza and Kavzoglub (2005) presented an approach for assessing the landslide risk potential, mainly for shallow landslides (Gomeza and Kavzoglub 2005). Some workers have made significant progress in calculation and extraction of spatial displacement field of landslide mass though analysis of high-resolution images and the use of the correlation coefficient method. For instance, in 2004, Delacourt et al. calculated landslide displacements using this method based on a number of Quick Bird Satellite images in different periods and mapped out the movement of the slope slide mass with an annual displacement of 2.5-20 m (Delacourt et al. 2004). In 2012, Travelletti et al. (2012) obtained the images of Super-Sauze slope slide at Alps using fixed highresolution optical camera and calculated the displacement of the sliding mass in 2008-2009. In 2014, Gance also made the measurement of the Super-Sauze slope slide using a novel object and landslide monitoring method coupled with image correlation method. Gance obtained the related images of the landslide movement in half a year in the area under study with optical camera, and placed white foam balls at surface for enhancement of contrast, and in this way, the landslide displacements were made known through Harris corner-point matching (Gance et al. 2014). As stated above, calculation of spatial landslide displacement field can be made using computer image recognition method based on high-resolution images. However, the correlation coefficient method previously used for matching images suffers the drawbacks of being difficult to make calculation and unsatisfactory in accuracy.

In view of the above mentioned facts, it is proposed to use the SIFT (scale-invariant feature transformation) algorithm for measurement of large-scale landslide displacement. With the use of SIFT, the cognominal points can be calculated through extraction of the features set of high-resolution images obtained in different phases and matching of images. This makes it possible to calculate the displacement field of landslide and define the extent of sliding mass.

\section{Methodology}

\subsection{Processing of remote sensing images}

\subsubsection{Ortho-rectification}

Satellite images, especially the images with large coverage area may undergo distortion during image-forming process because of earth curvature, terrain undulation and sensor altitude and angle of attitude (Luan et al. 2007). The distortion is attributed to the geometric deformation of the individual image points in varying degrees. The distortion of image can be eliminated through ortho-rectification. Therefore, when high-resolution image are used for calculating landslide displacements, the original images need to undergo ortho-rectification. This is done by making corrections of projection differences of original images using the digital elevation model (DEM) data (the images obtained and those to be corrected are consistent in extent) for converting the original image into orthogonal images.

\subsubsection{Registration of images}

Theoretically speaking, the coordinates of the stable points of the cognominal name observed by the same satellite at different times are consistent. Nevertheless, the stable points on two images may have positional errors due to the effects of satellite attitude, orbital error, structural performance of remote sensing instrument, movement and shape of the earth and the error produced by satellite ground stations in rough processing (Zhao et al. 2013). So, matching of images is necessitated. This is done in the following way: select one image among others as a reference for registration with another image, as the study of this paper is to define the landslide displacement field by using high-resolution image registration: (1) The ground control points selected should be uniformly distributed as much as possible; (2) Keep away from landslide area for avoiding offsetting the original deformation of sliding land; (3) Adequate ground control points should be available, otherwise, they are insufficient to serve as a basis for making error correction. The accuracy of registration is ascertained with the total root-mean-square-error (RMS error) as a measure. In general cases, the total RMS error should be controlled within one pixel on flat terrain and in hilly area, and should not exceed 2 pixels in mountain area. 


\subsection{Image matching}

\subsubsection{SIFT algorithm implementation}

SIFT is a feature matching-based algorithm (Lowe 1999, 2004). It was proposed by professor David GL of Columbia University in 1999 and was named scale-invariant feature transformation after improvement and perfection. SIFT has found widespread application in image splicing (Sun et al. 2014), and dynamic image tracking (Sun et al. 2010). It is an image of local feature extraction algorithm capable of performing translation, rotation, zooming of images and even keeping invariant in affine transformation. Its main feature is to transform the matching between images into similarity measure between characteristic vectors. It involves three steps: formation of scale space,generation of characteristic points descriptors and matching of characteristic vectors. The detailed description is shown in the document (Lowe 1999, 2004; Sun et al. 2010, 2014).

\subsubsection{Rejection of mismatching points}

The presence of background noise can possibly lead to mismatching of characteristic points. Such points need to be rejected. Mismatching points are characterized by the slope of the line connecting 2 images, which is obviously different from that of correctly matching points (Fig. 1a).
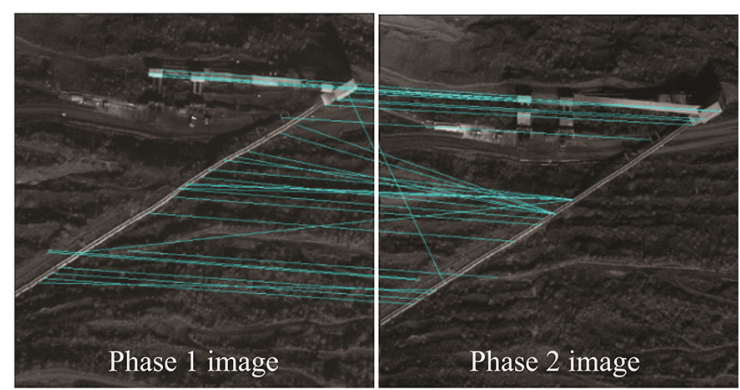

(a) Before rejection

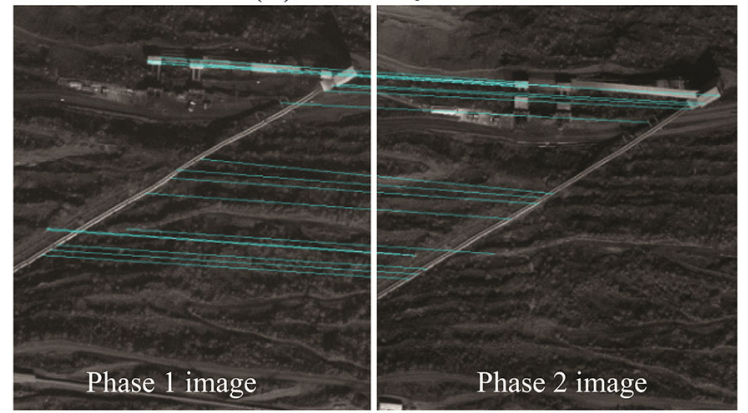

(b) After rejection

Fig. 1 Matching of feature points before and after rejection of mismatching points
Therefore, mismatching points can be rejected by making use of the above mentioned characteristics in a way as follows: calculate the slopes of the connecting lines of individual matching points, $k_{i}(i=1,2, \ldots n)$, and take the mean value $k$ as the true value to obtain the residual errors of individual matching points, $\gamma_{i}=k_{i}-k$. If the residual error of the slope $\left(\left|\gamma_{j}\right| \geq 3 \sigma\right)$ of the connecting line $j$ of a certain matching points is greater than 3 (standard error), the said matching points can be rejected as mismatching ones (Yang et al. 2014).

\subsection{Definition of landslide displacements}

By following the procedures as described above, the cognominal points in the images at different time periods are determined. The next step is to determine the displacements between two cognominal points. As the points have undergone displacements in the remote sensing images of different time periods, it is required to define the difference of the cognominal points in two images in image space coordinate systems, so as to determine the displacements of the points of the same in land sliding period. The method for calculating the displacements is as follows: calculate first the number of pixels between the cognominal points in two images, and then multiply the calculated value by the actual distance represented by individual points. The technical flow-sheet for defining the landslide displacements and extent is shown in Fig. 2.

\section{Application at Fushun west open mine}

\subsection{Overview of the study}

Located in Fushun city of China (Fig. 3), the West Open Mine is the largest opencast coal mine in Asia, with length of $6.6 \mathrm{~km}$, width of $2.2 \mathrm{~km}$ and depth of $500 \mathrm{~m}$. As a result of mining over 100 years, repeated landslides have occurred at the south and north slopes of the mine. Since 2010, in Qiantai mountain district of the mine's south slope, a ground fracture with a length of about $3100 \mathrm{~m}$ has appeared. In June 2014, the fracture reached a width of $40 \mathrm{~m}$ with the maximum drop of over $18 \mathrm{~m}$, and was seen to be moving northward rapidly at a rate of $8-10 \mathrm{~cm} /$ day. This leads to the presence of uplift at the bottom and damage of belt conveyors and nearby buildings under the effect of tensile strain (Fig. 4). Although GPS points were available for displacement monitoring, the extent of landslide displacement field failed to be defined because of the low density of monitoring points. D-INSAR was applied to observe the displacement field during the period of 2007-2011 and the information on the displacement field at the mine's south slope was obtained. However, following 


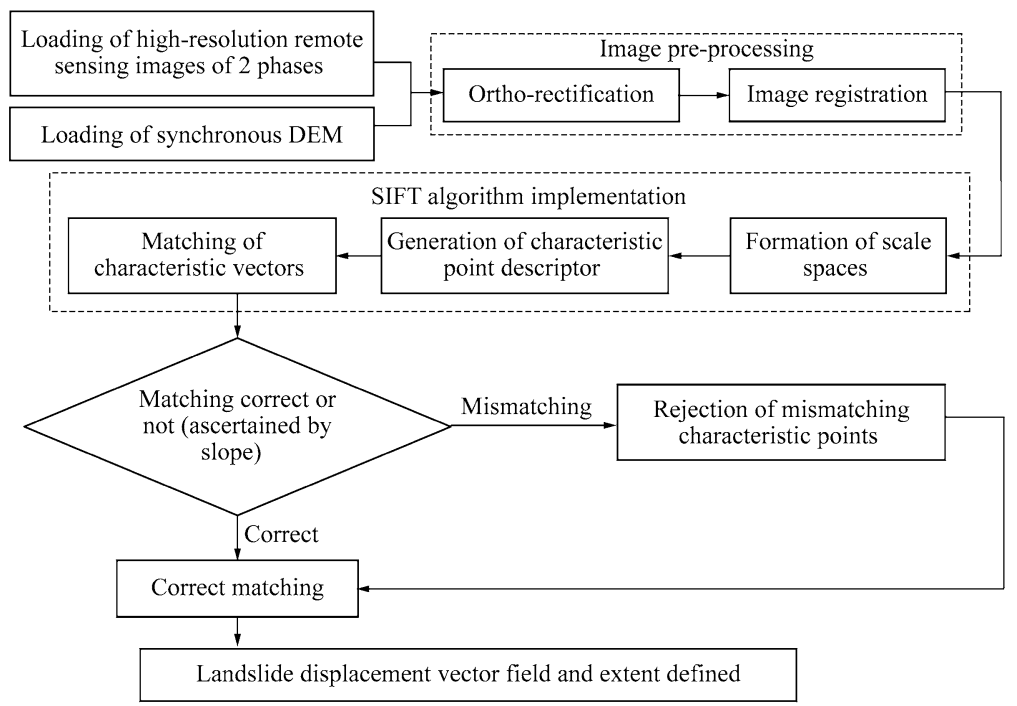

Fig. 2 Technical flow-sheet for defining landslide displacement vector field

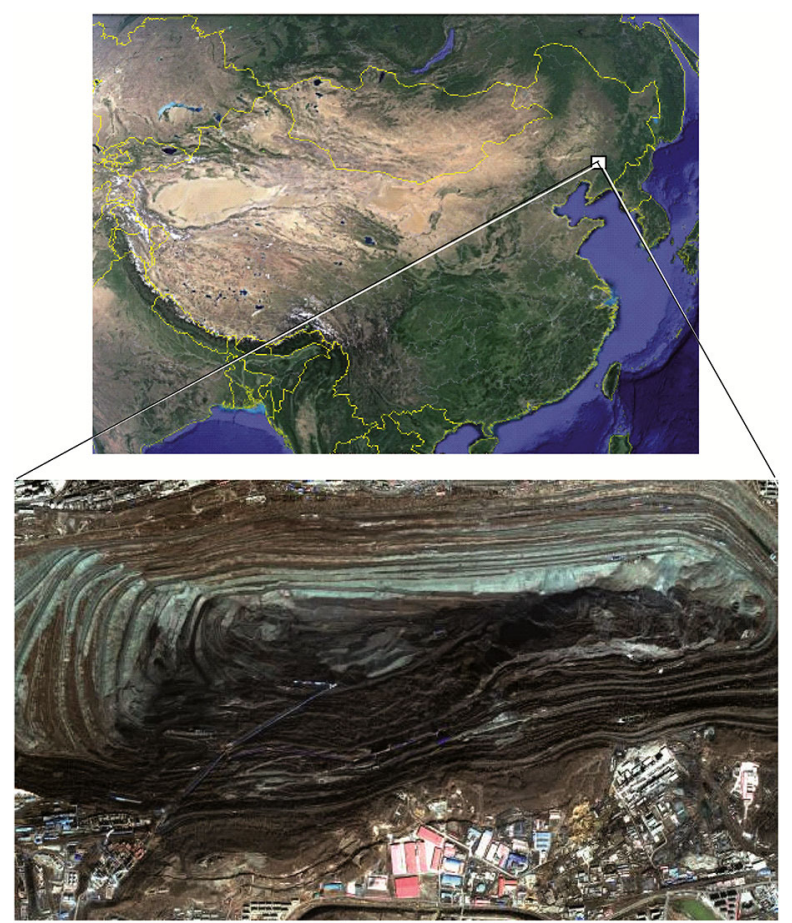

Fig. 3 Location map of the studied area

the entry into 2013, with the increase of displacements, the use of D-INSAR met with phase unwrapping trouble. Such being the case, the support of areal observation means is needed for the monitoring of extensive landslide displacement. Therefore, the high-resolution image-based method is applied for measuring displacement field and defining the extent of landslide.

\subsection{Data selection}

Pléiades 1 was successfully launched in December 17, 2011, and its revisit cycle is a day. It has 4 bands, respectively blue band, green band, red band and near infrared band, in addition to one panchromatic band. In the paper, the Pléiades 1B panchromatic band data with a spatial resolution of $0.5 \mathrm{~m}$ in 2 phases were selected as data source for measuring displacement field. The acquisition time of the two images was in the spring without vegetation, snow cover and cloud cover. The data of the 2 phases were recorded at 10:40 respectively on April 21, 2013 and March 18, 2014 (Table 1).

\subsection{Data processing}

For the images of the 2 phases, the following work is respectively made: ortho-rectification, registration, SIFT algorithm operation, rejection of mismatching points and definition of sliding displacement. Theoretically, for orthorectification of images, the DEM data should be obtained at the same time as that of the high-resolution images and make sure that their spatial resolutions are consistent. However, in actual ortho-rectification of images, their spatial resolutions are inconsistent. For the ortho-rectification of images in this paper, two kinds of DEM data can be used. These are the Aster DEM data in July 2010, actually measured by 3D laser scanning instruments respectively in November 2013 and August, 2014 (Table 2). The latter two are obviously higher in resolution. In order to enable the image data and DEM data to be consistent as much as possible in time, spatial resolution and surface features for reduced error, the image acquired 

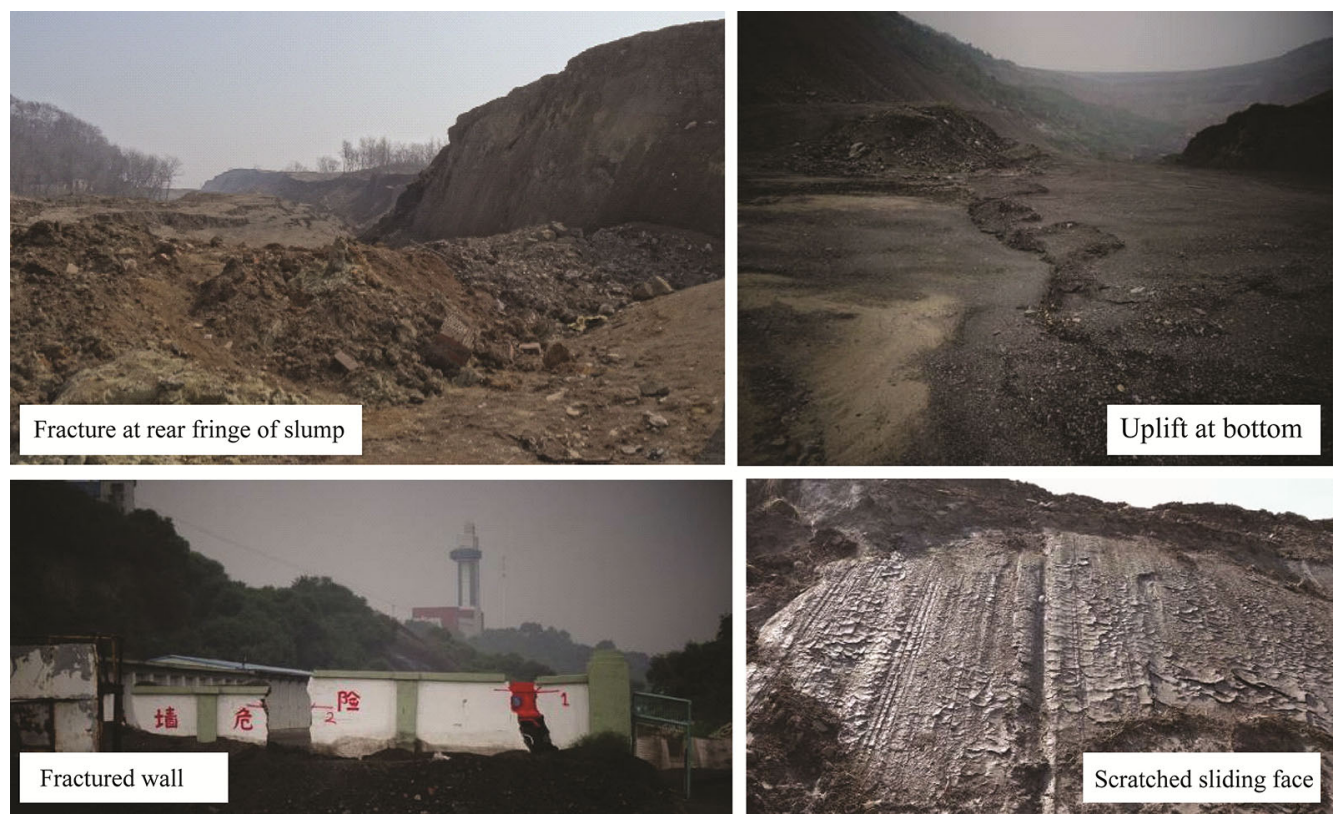

Fig. 4 Landslide-induced surface phenomena

Table 1 High-resolution image data source

\begin{tabular}{llllr}
\hline Data source & Image acquisition time & Orbit height $(\mathrm{km})$ & Resolution $(\mathrm{m})$ & Shooting angle $\left({ }^{\circ}\right)$ \\
\hline Pleiades full-color band & 2013.4 .21 & 694 & 0.5 & 17.7 \\
& 2014.3 .18 & 694 & 0.5 & 6.6 \\
\hline
\end{tabular}

Table 2 Information of the three kinds of DEM data

\begin{tabular}{lll}
\hline Time of data acquisition & Acquisition method & Spatial resolution (m) \\
\hline July 2010 & Aster 3D relative extraction & 30 \\
November 2013 & 3D laser scanning instrument point-cloud data generation & 0.5 \\
August 2014 & 3D laser scanning instrument point-cloud data generation & 0.5 \\
\hline
\end{tabular}

at April 21, 2013 was ortho-rectified using Aster DEM obtained in July, 2010, while, the image acquired at March 18, 2014 was ortho-rectified using DEM data from 3D laser scanning instrument obtained in November 2013.

Registration of images was made manually. For the images of 2013/4/21, the ortho-image of 2014/3/18 was taken as a reference, and the registration was made in a stable area around the pit with well-defined surface features such as the intersection of roads, corners of playground, farmland limits and river mouth as characteristic points.

\subsection{Monitoring result}

Through the processing procedures as described above, the vector diagram of the displacement field observed at the mine's south slope during the period of
2013.4.21-2014.3.18 was obtained (Fig. 5). In Fig. 5, the yellow arrows indicate the directions of the movement of targets. While the displacements are indicated by the lengths of the arrows. In Fig. 5a, the ground crack and the faults are shown by red lines.

It can be seen from Fig. 5, the area encompassed by ground cracks and faults is subjected to a larger displacement up to $37 \mathrm{~m}$. Outside this area, the displacement becomes smaller. As can be seen from Fig. 5, there exist Fault F5 at the eastern limit and Fault F2 at the western limit of the landslide. It is obvious that the development of the landslide towards the two sides is restricted by the presence of the two faults, a fact verified by actual ground investigation. The contour diagram of the displacements of sliding area is shown in Fig. 5b for better demonstration of the monitoring result. From this diagram, the extent of 


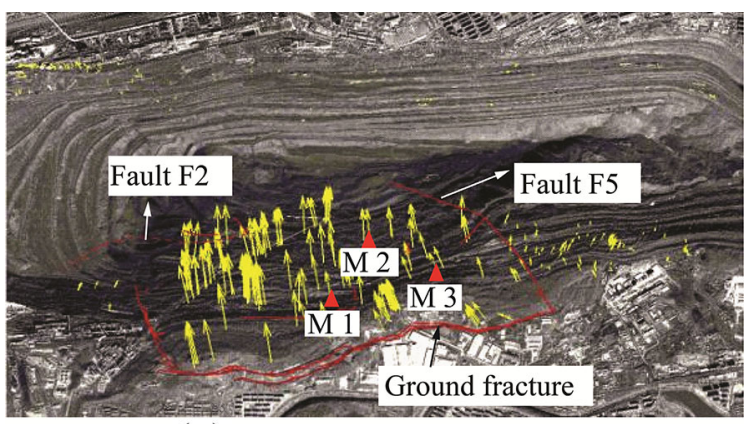

(a) Vector field of landslide

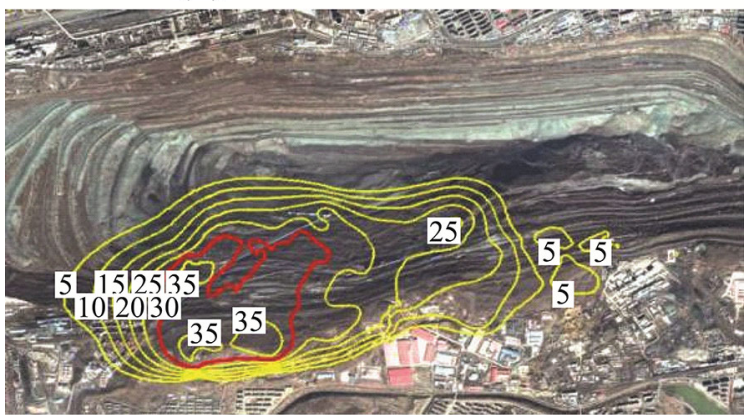

(b) Contour of landslide displacements

Fig. 5 Result of monitoring of landslide displacement field at Fushun west open mine

landslide and the displacements at individual points can be clearly observed.

\section{Accuracy evaluation}

For better evaluation of the monitoring method proposed in this paper and verification of the monitoring accuracy attained, the paper makes a comparison between the result so far obtained and the monitoring result made by GPS points arranged in the mining area (Fig. 5a). Table 3 shows the comparison results, and it indicates that: for the three monitoring points in contrast, M1 has an error of $0.9 \mathrm{~m}$ in south-to-north direction and $1.2 \mathrm{~m}$ in east-to-west direction, with a total error of $1.5 \mathrm{~m}$; M2 has an error of $1.9 \mathrm{~m}$ in south-to-north direction and $0.3 \mathrm{~m}$ in east-to-west direction, with a total error of $1.9 \mathrm{~m}$; M3 has an error of $0.2 \mathrm{~m}$ in south-to-north direction and $1.5 \mathrm{~m}$ in east-to-west direction, with a total error of $1.5 \mathrm{~m}$. As GPS monitoring is relatively high in accuracy (class: $\mathrm{mm}$ ), the result observed by GPS in this paper is taken as a true value. By comparison, the maximum error of the three points in south-tonorth direction is approximately $1.9 \mathrm{~m}$.

The result of the analysis of the error sources is as follows:

(1) For the ortho-rectification error, it comes from the following aspects:
High-resolution image not in step with DEM in time: The 1st-phase images were obtained in April 2013 while the DEM used for ortho-rectification was in July 2010. The 2nd-phase images were formed in March 2014 while the use of DEM was in November 2013. They were out of step with each other in time. Furthermore, in the above-mentioned time period, landslide displacement occurred in the study area. This led to the generation of error in ortho-rectification due to change of landform. Results of observation by GPS points M1, M2 and M3 indicate that during the period from November 2013 to March 2014, the vertical sliding displacements of the 3 points were 5.386, 4.701 and $4.880 \mathrm{~m}$ respectively. As the high-resolution image shooting angle was $6.60^{\circ}$, it can be inferred according to geometric principle of ortho-rectification (Fabio et al. 2009) that the errors produced by the 3 monitoring points in lateral displacement observation were 0.623 , 0.543 and $0.564 \mathrm{~m}$ respectively.

For the error of DEM, it is particularly the case of the 1st-phase data. The DEM data used for this phase were the relative data extracted from Aster sensor on TERRA ground observation satellite launched by NASA. It is relatively low in accuracy, with a horizontal accuracy of around $30 \mathrm{~m}$ and a vertical accuracy of approximately $20 \mathrm{~m}$. The DEM's low accuracy unavoidably adds to the error in orthorectification. Likewise, according to the geometric principle of ortho-rectification, and calculated at an image shooting angle of $17.7^{\circ}$ and the maximum vertical accuracy of $20 \mathrm{~m}$, it can be deduced that the maximum ortho-rectification error is up to $6.38 \mathrm{~m}$. Such an error brought about by DEM's low accuracy is most likely the major source of errors in landslide monitoring.

For the error of ortho-rectification algorithm, currently, the main models used for ortho-rectification involve affine transformation-based strict geometric models, collinear equation model, rational function model and polynomial model. However, in any case, the error is likely to occur because of their incapability to simulate the actual conditions.

(2) Error in image registration

In the study, the image registration was done by hand and it was strived to make the cognominal points to be uniformly distributed. However, in order to ensure that the coordinates of the points of the images in 2 phases were consistent, image registration was made only with the stable features around the surface mine as cognominal points while in the landslide area, unfortunately no such points can be used. Therefore, the points were uniformly 
Table 3 Comparison between the calculated results of SIFT algorithm and GPS points (eastward and southward: positive, westward and northward: negative)

\begin{tabular}{|c|c|c|c|c|c|c|c|}
\hline \multirow[t]{3}{*}{ GPS Point } & \multicolumn{4}{|c|}{ Displacement (m) } & \multirow{2}{*}{\multicolumn{2}{|c|}{ Difference (m) }} & \multirow[t]{3}{*}{ Total error } \\
\hline & \multicolumn{2}{|l|}{ GPS } & \multicolumn{2}{|c|}{ SIFT Algorithm } & & & \\
\hline & $\mathrm{S}-\mathrm{N}$ & $\mathrm{E}-\mathrm{W}$ & $\mathrm{S}-\mathrm{N}$ & E-W & $\mathrm{S}-\mathrm{N}$ & $\mathrm{E}-\mathrm{W}$ & \\
\hline M1 & 17.373 & -1.439 & 18.3 & -2.6 & 0.9 & -1.2 & 1.5 \\
\hline M2 & 20.501 & -2.434 & 22.4 & -2.1 & 1.9 & 0.3 & 1.9 \\
\hline M3 & 16.701 & -1.730 & 16.6 & -0.2 & -0.1 & 1.5 & 1.5 \\
\hline
\end{tabular}

distributed. This added to the error in registration in landslide area. Moreover, errors were also produced due to identification of points by naked eye.

(3) Error produced by SIFT algorithm The effect on measuring accuracy produced by SIFT algorithm is decided mainly by image quality (including, among others, spatial resolution, clarity and contrast) and the specific characteristics of SIFT algorithm. The remote sensing images used for measuring landslide displacements at Fushun West Open Mine are Pleiades panchromatic band data with a spatial resolution of $0.5 \mathrm{~m}$. In theory, the error produced by SIFT algorithm should be less than $0.5 \mathrm{~m}$ which can be reduced in case of higher image clarity and contrast.

It should be noted that the analysis of the source of errors as descried above is made on a factor by factor basis. In fact, these factors are interrelated. As there exists the possibility for them to counteract with one another, reduction of errors can be expected in this case. The total error is therefore, not a sum of individual errors. For example, in the operation of ortho-rectification, the error from high-resolution image not in step with DEM in time and the error from error of DEM may counteract with each other.

\section{Conclusions}

An approach for monitoring intensive landslide displacement using high-resolution remote sensing images and SIFT algorithm is proposed in the paper. Application of this method at Fushun West Open Mine indicates that:

(1) Generally, a landslide appears tiny deformation in the early stage, large deformation in the later stage, and accompanying fracture and swelling in the surface of the ground. The approach proposed in the paper is suitable for monitoring extensive spatial displacement field in the later stage of landslide. The method offers the merits of being low cost, easy to operate and high efficiency.
(2) A comparison between the proposed method and GPS in field monitoring at Fushun west open mine shows that the accuracy attained through the use of the method is $1.9 \mathrm{~m}$. Analysis of the cause of errors indicates that the errors not only stems from SIFT algorithm itself but also are closely related to orthorectification and registration of images, and more closely to DEM resolution and accuracy. So it is advised to use high-solution DEM data and to be in the same time with the remote sensing image.

Acknowledgments This work is supported by the National Basic Research Project of China (2011CB707102), the National Natural Science Foundations of China (41440032) and the Fundamental Research Funds for the Central Universities (N120801001).

Open Access This article is distributed under the terms of the Creative Commons Attribution 4.0 International License (http://crea tivecommons.org/licenses/by/4.0/), which permits unrestricted use, distribution, and reproduction in any medium, provided you give appropriate credit to the original author(s) and the source, provide a link to the Creative Commons license, and indicate if changes were made.

\section{References}

Brunner F, Macheiner K, Woschitz H (2007) Monitoring of deepseated mass movements. In: Proceedings of the third international conference on structural health monitoring of intelligent infra-structure. Vancouver, pp 13-16

Delacourt C, Allemand P, Casson B et al (2004) Velocity field of the "La Clapière" landslide measured by the correlation of aerial and Quick Bird satellite images. Geophys Res Lett 31(15):1-5

Fabio MA, Alexander PT, Konstantin VK et al (2009) Impact of ortho-rectification and spatial sampling on maximum NDVI composite data in mountain regions. Remote Sens Environ 113(12):2701-2712

Gance J, Malet JP, Dewez T, Travelletti J (2014) Target detection and tracking of moving objects for characterizing landslide displacements from time-lapse terrestrial optical images. Eng Geol 172(8):26-40

Ghuffar S, Szekely B, Boncat A, Pfeifer N (2013) Landslide displacement monitoring using 3D range flow on airborne and terrestrial LiDAR data. Remote Sens 5(6):2720-2745

Gómeza H, Kavzoglub T (2005) Assessment of shallow landslide susceptibility using artificial neural networks in Jabonosa River Basin, Venezuela. Eng Geol 78:11-27 
$\mathrm{Hu} \mathrm{H}, \mathrm{Hu} \mathrm{G}$ (2007) Advance in the application of InSAR on landslide research. Resour Environ Eng 5:15

Liu CJ, Liu HL, Zhang SF (2015) Study of slope deformation monitoring technology of precise comparison algorithm based on laser point cloud. Chin J Rock Mech Eng 34(Supp. 1):3281-3288

Lowe DG (1999) Object recognition from local scale-In-variant features. In: International conference on computer vision, Corfu

Lowe DG (2004) Distinctive image features from scale-invariant keypoints. Int J Comput Vis 60(2):91-110

Luan QZ, Liu HP, Xiao ZQ (2007) Comparison between algorithms of ortho-rectification for remote sensing images. Remote Sens Technol Appl 22(6):743-747

Nichol JE, Shaker A, Wong MS (2006) Application of high-resolution stereo satellite images to detailed landslide hazard assessment. Geomorphology 76:68-75

Prati C, Ferretti A, Perissin D (2010) Recent advances on surface ground deformation measurement by means of repeated spaceborne SAR observations. J Geodyn 49:161-170

Sun D, Roth S, Black MJ (2010) Secrets of optical flow estimation and their principles. In: IEEE computer society conference on computer vision and pattern recognition. San Francisco, California, pp 13-18

Sun YB, Zhao L, Huang SD, Yan L (2014) L2-SIFT: SIFT feature extraction and matching for large images in large-scale aerial photogrammetry. ISPRS J Photogramm Remote Sens 91:1-16

Sun Q, Zhang L, Ding XL, Hu J, Li ZW, Zhu JJ (2015) Slope deformation prior to Zhouqu, China landslide from InSAR time series analysis. Remote Sens Environ 156:45-57

Travelletti J, Delacourt C, Allemand P et al (2012) Correlation of multi-temporal ground-based optical images for landslide monitoring: application, potential and limitations. ISPRS Photogramm Remote Sens 70:39-55

Yang B, Li XD, Yan L, Yu YS (2014) Mosaic algorithm for aerial remote sensing image and its accuracy evaluation. Comput Eng 40(3):253-257

Zhao YS, Chen DM, Li XW et al (2013) The principle and method of analysis of remote sensing application. Science Press, Beijing, p 165 